\title{
ИННОВАЦИОННЫЕ ПОДХОДЫ РАЗВИТИЯ ПРЕДПРИНИМАТЕЛЬСТВА
}

\author{
Турсунов Имамназар Эгамбердиевич кандидат экономических наук, дочент \\ Курбанов Алишер Бобокулович кандидат экономических наук, дочент
}

Узбекистан, Каршинский инженерно-экономический институт

DOI: https://doi.org/10.31435/rsglobal_ijite/01062018/5675

\section{ARTICLE INFO}

Received 24 April 2018

Accepted 26 May 2018

Published 01 June 2018

KEYWORDS

Innovative,

economy,

modernization,

small business,

entrepreneurship

\begin{abstract}
The paper recommends working out a comprehensive state program on innovative development of the Uzbekistan's economy for medium and long term perspective. The framework of equal economic conditions legislatively created for enterprises irrespective of their forms of ownership opens up the possibilities for an unbiased assessment of the advantageous forms of production organization. Competition between enterprises with various forms of ownership encourages the improvement of the internal system of production management, technical retooling, the improvement of the responsiveness to new achievements in science and technology, of manufacturing the better quality goods at low costs and cheaper prices In the long run this proves to be a powerful lever of economic, scientific and technological progress. The issues of the formation of innovative model of small-scale business end entrepreneurship development, elaboration of concrete forms and methods of state regulation of innovations, carried out by entrepreneurial structures that will provide the innovative tendency of national economy are considered in the article.
\end{abstract}

Перспективы развития Узбекистана связаны с формированием инновационной экономической системы, которая призвана обеспечить повышение инновационной активности хозяйствующих субъектов и рост их числа для обеспечения технологической модернизации предприятий, повышения конкурентоспособности национальной экономики и, в конечном счете, роста благосостояния и качества жизни населения.

Как показывает мировая практика, функционирование наиболее преуспевающих экономических систем, высокую конкурентоспособность и стабильный экономический рост, прежде всего, обеспечивают факторы, стимулирующие распространение новых технологий. С нашей точки зрения, учитывая то обстоятельство, что современные конкурентные преимущества практически полностью обеспечиваются за счет преимуществ в технологиях производства, управления, организации продвижения товаров, успешное развитие конкурентоспособности экономической системы возможно при комплексном использовании современных концепций инновационного развития.

По своей внутренней логике инновации - это новый момент в жизни предприятий, основа экономического успеха и обеспечения их выживаемости в условиях конкуренции. Это хорошо усвоили зарубежные промышленные компании, фирмы, корпорации. Они делают немалые затраты на инновационные разработки. Например, в США эти затраты составляют $2,8 \%$ к ВВП, Великобритании - 1,9\%, Швеции - 3,8 \%. Японские промышленные компании отчисляют на научные исследования и разработки до 10 \% от всего объёма продаж, понимая, что наибольшую прибыль, выгоду приносят товары изготовленные с применением современных передовых технологий.

Как показывают наблюдения, Узбекистан не стоит в стороне от мирового прогресса. В стране инновация придаётся внимания ни меньше, если не больше, чем за рубежом. Этому способствуют не только имеющиеся в республике огромные природные и трудовые ресурсы, интеллектуальный потенциал, но и принимаемые на государственном уровне меры по совершенствованию координации и управления развитием науки и технологии, стимулированию внедрения инновационных проектов и технологий в отечественное производство, дальнейшему совершенствованию инвестиционного климата и деловой среды в стране. 
В республике ежегодно проводятся ярмарки инновационных проектов, идей и технологий, в которых участвуют представители не только отечественных, но и зарубежных предприятий, фирм и компаний. Так, в ходе состоявшихся в 2008-2015 годах ярмарок было представлено около 3900 инновационных идей и технологий, созданных ученными нашей страны, подписано более 3100 договоров, в результате реализации которых произведено новой продукции почти на 1,8 трлн. сум.

Принятые за последнее время меры уже сказались на состоянии деловой среды для малого бизнеса. Одним из главных преимуществ малого бизнеса является то, что он неизбежно ведет к появлению конкуренции на отечественном рынке, что в свою очередь благоприятно влияет на темпы экономического развития страны. Стратегия действий по пяти приоритетным направлениям развития Республики Узбекистан в 2017-2021 годах реализуется в 5 этапов, каждый из которых предусматривает утверждение отдельной ежегодной Государственной программы по ее реализации в соответствии с объявляемым наименованием года. Объявление 2018 года поддержки активного предпринимательства, инновационных идей и технологий имеет большое значение для развития всех отраслей экономики[1].

За годы независимости Узбекистана данный сектор экономики получил значительное развитие, однако здесь имеется много слабых мест, как со стороны предпринимателей, так и с точки зрения управления национальной экономикой. Следует отметить недостаточную активность предпринимательства и зачастую неквалифицированный подход к этой деятельности. Не хватает современных инновационных подходов, использования прогрессивных технологий, ориентированных на активное развитие сферы деятельности. Об этом подчеркнул Президент Узбекистана Ш.М.Мирзиёев: «Когда мы говорим «активные предприниматели», мы подразумеваем деловых людей, способных производить конкурентоспособную продукцию, самое важное - создающих новые рабочие места, приносящих пользу не только себе и своей семье, но и всему обществу». [2].

В современных условиях устойчивое развитие страны возможно только на основе активизации инновационных процессов во всех сферах экономики. В значительной степени это обусловлено необходимостью учета специфических особенностей страны при определении приоритетных направлений инвестиционной политики, направленной на формирование и реализацию инновационного потенциала страны.

Интенсивный рост экономики Узбекистана в условиях модернизации возможен только при переходе на инновационный путь развития, который позволит получить конкурентные преимущества на мировом рынке. Инновационный путь развития обеспечивается путем создания инфраструктуры инновационного бизнеса, т.е. совокупность учреждений и институтов, обеспечивающих технологический трансферт. Кроме того, инфраструктура представляет собой комплекс рыночных и инновационных институтов и элементов. Мировые тренды развития показывают, что экономика является инновационной, когда:

- доступ к информации о новых знаниях, инновациях, результатах инновационной деятельности обеспечивается посредством современных информационных технологий;

- уровень развития инфраструктур в стране в целом соответствует задачам создания национальных информационных ресурсов, необходимых для поддержания научнотехнического прогресса и инновационного развития;

- расширения инновационной деятельности в разных сферах происходит на основе радикальных изменений социальных структур и институтов развития общества;

- новые идеи, знания, технологии воспринимается обществом доброжелательно благодаря развитым компенсационным механизмам снижения сопротивления изменениям;

- необходимые в данный момент времени инновации, основанные на высоких производственных технологиях, оперативно реализуются, благодаря развитым инновационным инфраструктурам;

- эффективно реализуются соответствующие основным направлениям мирового технологического развития комплексные проекты развития региона, опираясь на гибкую систему опережающей подготовки и переподготовки специалистов в области инноваций и инновационной деятельности.

Создание новых инновационных структур - одна из основных задач экономической политики как экономически развитых стран, так и развивающихся. Эти структуры позволяют стабилизировать экономическую ситуацию. Даже в развитых экономических системах они в ряде случаев создаются в период экономического спада, структурной перестройки, 
сопровождающихся сокращением рабочих мест, уменьшением объемов бюджетных ассигнований на научное развитие в условиях значительного накопления научно-технического потенциала при отсутствии механизма доведения имеющихся идей до конкретного потребителя и достижения коммерческого успеха. Инновационные структуры нового типа в ряде случаев возникли как условие выхода из кризисной ситуации.

Инновационная структура представляет собой сложную социально-экономическую систему, состоящую из большого числа элементов. Данная система характеризуется разнообразными взаимосвязями, их изменчивостью, наличием у каждого из субъектов данной системы определенных интересов, в некоторых случаях противоречащих друг другу. Очевидно, что эффективность указанной системы определяется результативностью функционирования инновационной инфраструктуры, координирующими элементами которой может стать научнотехнические парки, малые инновационные предприятия (МИП), бизнес-инкубаторы, технополисы, центры высоких технологий, технопарки и т. п.

Дальнейшее развитие трансфера технологий в большей степени зависит от создания эффективной системы инновационной инфраструктуры. Инфраструктура инновационной деятельности или инновационная структура подразумевает комплекс организационноэкономических институтов, непосредственно обеспечивающих условия для реализации хозяйствующими субъектами трансфера технологий в процессе производства на основе принципов экономической эффективности.

При формировании рыночных отношений инновационная инфраструктура является средой, способной снизить неопеделенность инновационных процессов и благоприятствующей рисковой деятельности. В этом качестве она выступает как в отношении отдельного хозяйственного субъекта (фирмы), так и целого региона. Инновационная инфраструктура аккумулирует финансовые ресурсы, действуя как инвестиционный механизм инновационных процессов, объединяет капиталы институциональных инвесторов, при этом не только финансируются высокие технологии и наукоемкое производство, но и берется плата за риск, то есть риск выступает в качестве объекта купли-продажи. В рамках инфраструктуры получают значительное развитие такие инновационные организации, как научно-технические парки, малые инновационные предприятия (МИП), бизнес-инкубаторы, технополисы, центры высоких технологий и т.п.

В Узбекистане созданы структуры, направленные на поддержку инновационных предприятий. Также созданы центры в ряде высших учебных заведений страны, в научноиследовательных организациях, на крупных промышленных предприятиях. Центры инновационной деятельности и трансфера технологий также имеются в каждой области.

Вместе с научными организациями и университетами, с одной стороны, промышленностью и бизнесом - с другой, областные центры инновационной деятельности и трансфера технологий могут на местах формировать информационно-кооперационную инфраструктуру инноваций, которая впоследствии органично сможет влиться в национальную сеть трансфера технологий. Наличие национальной сети трансфера технологий на сегодняшний день является одним из ключевых компонентов инновационной структуры в рамках национальной инновационной системы.

Важно отметить, что создание инновационных центров зависит от уровня технологического и экономического развития национальной экономики. В странах, имеющих развитую производственную инфраструктуру, наблюдается процесс, характеризующийся повышением роли нематериальных факторов производства, информатизации общества. Тем самым формируются реальные возможности создания сети консалтинговых, инжиниринговых, сервисных, информационных услуг, способствующих поддержке инновационных процессов. В целом, следует отметить, что в условиях современного развития общества инновационная инфраструктура должна способствовать повышению роли науки в развитии предпринимательства и производства в целом.

В процессе поиска путей дальнейшего развития предпринимательства в Узбекистане, его финансовой стабильности актуализируется проблема форм и методов интеграции и кооперации малых инновационных предприятий. Кроме того, переход экономики страны на новый тип экономического роста делает жизненно необходимыми исследования по формированию и развитию предпринимательства как основного фактора инновационного развития.

В рыночной экономике основная масса инноваций реализуется предпринимательскими структурами как средство решения производственных и коммерческих задач. Поиск и внедрение новых технологий, новых видов продукции с улучшенными потребительскими 
характеристиками, постановка и решение нестандартных задач хозяйственного развития обеспечиваются посредством реализации таких функций предпринимательства, как инновационность, творчество, новаторство и готовность к риску. Само зарождение и разработка инновации, ее воплощение, реализация и использование так же являются объектом предпринимательской деятельности.

Инновационной экономика становится тогда, когда нововведения служат основой экономического развития: экономический интерес предпринимателей состоит в продвижении инноваций, а инновации определяют важнейшие направления развития предпринимательской деятельности. Поэтому решение проблемы инновационной трансформации национальной экономики напрямую связано с использованием предпринимательства как фактора производства, необходимого для организации инновационного производства на основе как государственной, так и частной формы собственности. Такой подход, а также учет соответствующей социально-экономической среде ведущей роли государства в экономике, в соответствии с которой предпринимательство выступает не только частной инициативой, а составляющей государственной экономической политики, обусловливают исследование особенностей предпринимательской деятельности в национальной экономике.

Исследование западных экономистов убедительно показывает, что, во-первых, малые и средние фирмы обеспечивают более двух третей занятости и национального дохода в ведущих странах мира. Во-вторых, только оптимальное сочетание крупных и малых фирм позволяет поддерживать высокие темпы научно-технического и экономического прогресса. В-третьих, малые фирмы в наукоёмких секторах промышленности являются наиболее активными субъектами инновационного процесса, выполняют очень большой объём доработки, модификации, рыночного освоения результатов крупных открытий, совершённых силами большой науки [3, с. 6].

Создание инновационной инфраструктуры зависит от уровня технологического и экономического развития национальной экономики. В условиях трансформированного общества инновационная инфраструктура должна способствовать вхождению науки в рыночную среду, развитию предпринимательства в научно-технической сфере, поэтому ее формирование во многом определяется состоянием рыночной инфраструктуры.

\section{ЛИТЕРАТУРА}

1. Указ Президента № УП-4947 от 7.02.2017г. «Стратегия действий по пяти приоритетным направлениям развития Республики Узбекистан в 2017-2021 годахџ.

2. Послание Президента Республики Узбекистана Ш.М.Мирзиёева депутатам Олий Мажлиса. Газета «Народное слово» 2017 год 23 декабрья № 258 (6952).

3. Засименко Б. В. Современное формы организации инновационной деятельности предприятий: Научное издание. -М.: Информационно-внедренческий центр «Маркетинг», 2007.-16c. 